\title{
Presence of multiple coronary angiographic characteristics for the diagnosis of acute coronary thrombus
}

\author{
Alok R. Amraotkar ${ }^{1 *}$, Shahab Ghafghazi ${ }^{1 *}$, Patrick J. Trainor ${ }^{2,3}$, Charles W. Hargis ${ }^{4}$, \\ Affan B. Irfan ${ }^{1}$, Shesh N. Rai ${ }^{2,3}$, Aruni Bhatnagar ${ }^{1}$, Andrew P. DeFilippis ${ }^{1,5,6}$ \\ ${ }^{1}$ Division of Cardiovascular Medicine, University of Louisville, Louisville, Kentucky, United States \\ ${ }^{2}$ Department of Bioinformatics and Biostatistics, University of Louisville, Louisville, Kentucky, United States \\ ${ }^{3}$ Biostatistics Shared Facility, J.G. Brown Cancer Center, University of Louisville, \\ Louisville, Kentucky, United States \\ ${ }^{4}$ School of Medicine, University of Louisville, Louisville, Kentucky, United States \\ ${ }^{5}$ KentuckyOne Health, Jewish Hospital, Louisville, Kentucky, United States \\ ${ }^{6}$ Ciccarone Center for the Prevention of Heart Disease, Johns Hopkins University, \\ Baltimore, Maryland, United States
}

\begin{abstract}
Background: Coronary angiography is frequently employed to aid in the diagnosis of acute coronary thrombosis, but there is limited data to support its efficacy. The aim of the study was to evaluate sensitivity and specificity of five commonly used angiographic characteristics for diagnosis of acute coronary thrombosis: Ambrose complex lesion morphology; spherical, ovoid, or irregular filling defect; abrupt vessel cutoff; intraluminal staining; and any coronary filling defect.

Methods: Coronary angiography of 80 acute myocardial infarction or stable coronary artery disease subjects were assessed in blinded fashion, for the presence or absence of five angiographic characteristics. Only lesions of $\geq 10 \%$ stenosis were included in the analysis. Presence or absence of each angiographic characteristic was compared between lesions with or without the following study defined outcomes: 1) histologically confirmed thrombus, 2) highly probable thrombus, and 3) highly unlikely thrombus.

Results: A total of 323 lesions were evaluated. All studied angiographic characteristics were associated with histologically confirmed and highly probable thrombotic lesions vs. lesions not meeting criteria for these outcomes ( $p<0.03$ ), except for complex Ambrose morphology which was not associated with any of the study outcomes $(p>0.05)$. Specificity for identifying histologically confirmed or highly probable thrombotic lesion was high (92-100\%), especially for spherical, ovoid, or irregular filling defect (99-100\%) and intraluminal staining (99\%). Sensitivity for identification of histologically confirmed or highly probable thrombotic lesions was low for all tested angiographic characteristics (17-60\%).

Conclusions: The presence of spherical, ovoid, or irregular filling defect or intraluminal staining was highly suggestive of coronary thrombus. However, none of the evaluated angiographic characteristics were useful for ruling out the presence of coronary thrombus. If confirmed in an independent cohort, these angiographic characteristic will be of significant value in confirming the diagnosis of acute coronary thrombosis. (Cardiol J 2017; 24, 1: 25-34)
\end{abstract}

Key words: atherothrombosis, acute coronary thrombus, acute coronary syndrome, myocardial infarction, coronary angiography

Address for correspondence: Andrew Paul DeFilippis, MD, MSc, Division of Cardiovascular Medicine, University of Louisville, 550 S. Jackson St, ACB 3rd Floor, Louisville, KY, USA 40292, fax: +1-502-852-8070, e-mail: apdefi01@louisville.edu

*A.R. Amraotkar and S. Ghafghazi are co-first authors.

Received: 08.09.2016 Accepted: 04.12.2016 


\section{Introduction}

Acute myocardial infarction (MI) remains a leading cause of death worldwide. It is most often a result of atherosclerotic plaque disruption (erosion or rupture), accompanied by thrombus formation that results in obstruction of blood flow, tissue ischemia and necrosis [1]. Although significant advancements have been made using biomarkers and electrocardiograms (ECGs) to diagnose acute MI, these methods measure the end result (i.e., myocardial necrosis) and not the cause and therapeutic target, coronary thrombosis. There are several common non-thrombotic causes of MI (e.g., demand ischemia, stress cardiomyopathy), with varying therapeutic and prognostic implications [2]. Hence, these measurements cannot distinguish tissue necrosis caused by coronary thrombosis from other causes of necrosis such as demand ischemia or stress cardiomyopathy [2]. Even in the most fulminant manifestation of MI, acute ST-elevation MI (STEMI), $14 \%$ of subjects have no identifiable culprit lesion on angiography when conservatively defined as no lesion with $>70 \%$ stenosis [3]. Additionally, while circulating levels of cardiac proteins such as cardiac troponin are specific indicators of myocardial necrosis, the levels of these proteins often do not increase for several hours subsequent to the initial acute MI delaying diagnosis [4]. Therefore, current diagnostic criteria for acute MI often fail to confirm the diagnosis prior to the induction of irreversible myocardial necrosis, even with highly sensitive cardiac troponin assays [5].

Coronary angiography remains the standard diagnostic tool for evaluating patients suspected of acute coronary thrombus. The third universal definition of acute MI identifies angiographic confirmation of coronary thrombus as a criterion for the diagnosis of acute MI [6]. However, there is limited data available concerning the sensitivity and specificity of angiography for presence or absence of coronary thrombus.

The goal of the present study is to evaluate the utility of five commonly used angiographic characteristics (Ambrose complex lesion morphology; spherical, ovoid, or irregular filling defect; abrupt vessel cutoff; intraluminal staining; and any coronary filling defect) in identifying the presence of an acute coronary thrombus in 80 subjects with acute MI or stable coronary artery disease (CAD) undergoing coronary angiography.

\section{Methods}

\section{Study design and population}

Between March 2012 and September 2013, 80 acute MI or stable CAD patients (Supplemental Table 1 - see journal website) undergoing coronary angiography at KentuckyOne Health Jewish Hospital or the University of Louisville Hospital (Louisville, Kentucky, United States) were prospectively enrolled in the study prior to coronary angiography. Patients who received fibrinolytic therapy prior to coronary angiography were not eligible. The study protocol was approved by the institutional review board and all subjects provided informed written consent. All ECGs were systematically evaluated according to established criteria by a single board-certified cardiologist [6-9].

\section{Coronary angiography}

Angiograms were systematically evaluated in all subjects by an experienced team of one technician and one board certified interventional cardiologist, blinded to all other subject data. All reported values represent a consensus opinion from the Angiographic Core Laboratory, Johns Hopkins University (Baltimore, Maryland). Angiographic scoring (Supplemental Figure 1 - see journal website) was developed prior to assessment, to include the evaluation of angiographic characteristics reported in the literature (Supplemental Figure $2-$ see journal website) for detection of a coronary thrombus [10-18]. The presence of following five angiographic characteristics were defined a priori as independent variables: 1$) \mathrm{com}$ plex Ambrose lesion morphology (Fig. 1A) [12, 19]; 2) spherical, ovoid, or irregular intramural filling defect (Fig. 1B) [13]; 3) abrupt vessel cutoff with persistence of contrast (Fig. 1C) [16]; 4) intraluminal staining (Fig. 1D) [18]; 5) any coronary filling defect (includes spherical, ovoid, irregular, hazy, or occlusive filling defects and obstructive coronary dissections) (Fig. 1E) [19]. Lesions may have one or more of the aforementioned angiographic characteristics.

\section{Determination of individual lesions}

Individual lesions were defined as lesions in a distinct vessel branch or separated by $>3 \mathrm{~cm}$ of normal vessel ( $<10 \%$ stenosis). The most severe portion of the lesion was used for grading the lesion. All lesions with $\geq 10 \%$ stenosis were evaluated. Lesion numbers were recorded on the 


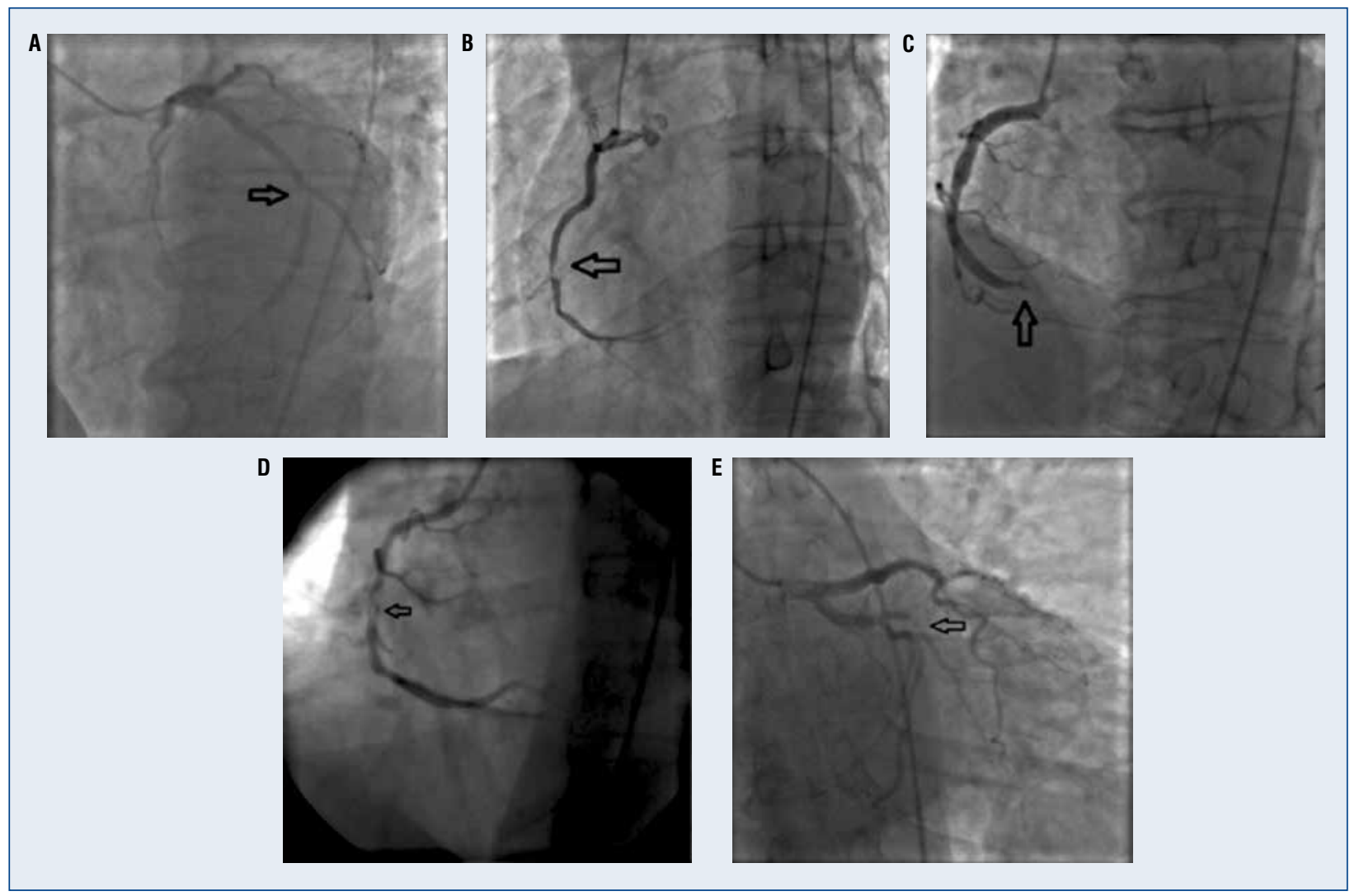

Figure 1. Studied angiographic characteristics; A. Complex Ambrose morphology; B. Spherical, ovoid or irregular filling defect; C. Abrupt vessel cutoff; D. Intraluminal staining; E. Any coronary filling defect, which includes spherical, ovoid, irregular, hazy, occlusive filling defects and obstructive coronary dissections.

basis of their location on the 29-segment coronary artery map (Supplemental Figure 3 - see journal website) [17]. The ramus intermedius was considered to be part of the left anterior descending coronary artery territory.

\section{Histological and biochemical analysis}

The standard of care at the enrollment sites was to attempt coronary aspiration thrombectomy when an acute coronary thrombus was suspected. Aspiration thrombectomy was left to the discretion of the treating interventional cardiologist. All aspiration thrombectomy attempts were immediately filtered and preserved in formalin for histological evaluation by a pathologist at CVPath, Inc. (Gaithersburg, Maryland) blinded to all other data. Ortho Vitros 5600 assay at the University of Louisville Hospital and Beckman Access assay at the KentuckyOne Health Jewish Hospital, were used to measure troponin levels and confirm the diagnosis of acute MI. Troponin criteria for outcomes are detailed in the supplement
(Supplemental Methods, Biochemical Data see journal website).

\section{Outcome groups}

Lesions from each subject were categorized into three outcome groups (Table 1). Group 1 consisted of lesions with histologically confirmed thrombus ( $\leq 4$ days old). Group 2 consisted of lesions that were highly probable to contain coronary thrombus - lesions with histologically confirmed thrombus $\leq 4$ days old (all lesions in Group 1) PLUS lesions with $>70 \%$ stenosis and corresponding elevated troponin and ST-segment elevation on the ECG in territory of the vessel. Group 2 was created to mitigate for the selective coronary aspiration thrombectomy in our cohort and the potential failure of aspiration thrombectomy to capture an existing thrombus [20]. Group 3 consisted of lesions highly unlikely to have a coronary thrombus - no histologically confirmed thrombus recovered, no troponin elevation AND no ST-segment elevation or depression on the ECG. 
Table 1. Classification of coronary thrombosis outcome groups.

\begin{tabular}{|c|c|c|c|}
\hline \multirow[t]{2}{*}{ Study lesion types } & \multicolumn{3}{|c|}{ Requirements } \\
\hline & Thrombus & Peak troponin & Electrocardiogram and angiogram \\
\hline $\begin{array}{l}\text { Group } 1 \\
\text { Histologically } \\
\text { confirmed coronary } \\
\text { thrombus }\end{array}$ & $\begin{array}{l}\text { Histologically con- } \\
\text { firmed thrombus } \\
\text { of age } \leq 4 \text { days } \\
\text { aspirated }\end{array}$ & - & $\begin{array}{c}\text { Thrombus aspirated from coronary } \\
\text { vessel (LM, LAD, LCX, RCA } \\
\text { or graft) }\end{array}$ \\
\hline $\begin{array}{l}\text { Group } 2^{*} \\
\text { Highly probable } \\
\text { coronary thrombus }\end{array}$ & $\begin{array}{l}\text { Histologically con- } \\
\text { firmed thrombus } \\
\text { of age } \leq 4 \text { days } \\
\text { aspirated }\end{array}$ & $\begin{array}{c}\frac{\text { Beckman Access assay }}{\text { "Peak" troponin level }} \\
>0.5 \mathrm{ng} / \mathrm{mL} \\
\text { Ortho Vitros } 5600 \text { assay } \\
\text { "Peak" troponin level } \\
>0.12 \mathrm{ng} / \mathrm{mL}\end{array}$ & $\begin{array}{l}\text { ST-segment elevation in territory } \\
\text { of vessel (LM, LAD, LCX, RCA } \\
\text { or graft) with > 70\% stenosis }\end{array}$ \\
\hline $\begin{array}{l}\text { Group } 3 \\
\text { Highly unlikely to } \\
\text { have a coronary } \\
\text { thrombus }\end{array}$ & $\begin{array}{l}\text { No histologically } \\
\text { confirmed throm- } \\
\text { bus recovered }\end{array}$ & $\begin{array}{c}\frac{\text { Beckman Access assay }}{\text { "Peak" troponin level }} \\
<0.04 \mathrm{ng} / \mathrm{mL} \\
\text { Ortho Vitros } 5600 \text { assay } \\
\text { "Peak" troponin level } \\
<0.035 \mathrm{ng} / \mathrm{mL}\end{array}$ & $\begin{array}{l}\text { No ST-segment elevation } \\
\text { or depression }\end{array}$ \\
\hline
\end{tabular}

*Should satisfy requirements for: [Thrombus] OR [Peak Troponin, ECG and Angiogram]; LAD — left anterior descending coronary artery; LCX - left circumflex coronary artery; LM — left main coronary artery; RCA — right coronary artery; NA — not applicable

\section{Ethics statement}

Informed and signed consent was obtained for all subjects enrolled and this study was approved by the University of Louisville's Institutional Review Board. This submission complies with the ICMJE ethics and STROBE guidelines.

\section{Statistical analysis}

The primary outcome of this study was based on a lesion-level analysis of angiographic characteristics for the detection of thrombotic lesions. Frequencies, percentages, and Fisher's exact test p-values are reported for comparing categorical characteristics between subject groups. Means, standard deviations, and p-values from Student $t$-test or Wilcoxon rank-sum tests (as appropriate) are reported for comparing continuous characteristics between groups.

In the case of a zero-count (or very low event count) of characteristic(s) in the cell, an absolute relationship would be established between the characteristic(s) and the occurring group, and therefore the odds would not be computable [21]. Under these conditions, conservative odds ratio estimates would be generated by adding one event to the zerocount (or very low event count) cell of the group.

\section{Primary endpoints}

The primary endpoints of this study were the independent association of the presence of angiographic characteristics with the three studydefined outcome groups. This evaluation was accomplished by comparing the frequencies of angiographic characteristics in lesions with histologically confirmed thrombus (Group 1) vs. all lesions without histologically confirmed thrombus (Not-Group 1); lesions highly probable to contain coronary thrombus (Group 2) vs. all lesions not highly probable of having a thrombus (Not-Group 2) and lesions highly unlikely to have a coronary thrombus (Group 3) vs. all lesions not highly unlikely to have a thrombus (Not-Group 3). These analyses are further described in the supplement (Supplemental Methods, Primary Endpoints - see journal website). Lesions in Group 1 or Group 2 were considered as thrombotic lesions and lesions in Group 3, Not-Group 1 or Not-Group 2 were considered as non-thrombotic lesions.

\section{Results}

Angiograms were analyzed for all 80 subjects enrolled in the study. Four subjects did not have any lesions with $\geq 10 \%$ stenosis and therefore did not qualify for lesion analysis; these subjects had non-thrombotic MI presentations (e.g., demand ischemia). Seventy-six subjects had a total of 323 individual lesions ( $\geq 10 \%$ stenosis). A total of 27 thrombus aspirations were attempted from distinct lesions, of which 23 (85\%) were confirmed 
as thrombus on histopathology (Group 1). Thirty subjects had a total of 73 lesions that qualified for Group 2, and 18 subjects had a total of 61 lesions that qualified for Group 3. The clinical characteristics of the subjects in this cohort are presented in Table 2.

\section{Complex Ambrose morphology}

Complex Ambrose morphology was not associated with histologically confirmed coronary thrombus (Group 1 vs. Not-Group 1, p > 0.5), highly probable coronary thrombus (Group 2 vs. Not-Group 2, $\mathrm{p}>0.5$ ), nor was the absence of complex Ambrose morphology associated with absence of coronary thrombus (Group 3 vs. Not-Group 3, $\mathrm{p}>0.5$, Tables $3-5)$.

\section{Spherical, ovoid or irregular filling defect}

Spherical, ovoid, or irregular filling defect was present in $39 \%$ of histologically confirmed thrombotic lesion (Group 1) as compared to $1 \%$ of lesions without a histologically conformed thrombus (Not-Group 1) (OR = 206, 95\% CI 36.5-1161, $\mathrm{p}<0.0001$, Table 3). Similarly, it was present in $14 \%$ of lesions that were highly probable for coronary thrombus (Group 2) as compared to $<1 \%$ of lesions that were not highly probable for coronary thrombus (Not-Group 2) (OR $=60.8$, 95\% CI 3.84-961, $\mathrm{p}=0.004$, Table 4). Spherical, ovoid, or irregular filling defect was not present in any lesions classified as highly unlikely to have a coronary thrombus (Group 3) (Table 5). Spherical, ovoid, or irregular filling defect was $22-55 \%$ sensitive and 99-100\% specific for histologically confirmed or lesions highly probable for coronary thrombosis (Tables 3,4 ).

\section{Abrupt vessel cutoff with persistence of contrast}

Abrupt vessel cutoff with persistence of contrast was present in $61 \%$ of histologically confirmed thrombotic lesions (Group 1) as compared to $8 \%$ of lesions without a histologically confirmed thrombus (Not-Group 1) $(\mathrm{OR}=18,95 \%$ CI 6.64-49.1, $\mathrm{p}<0.0001$, Table 3$)$. Abrupt vessel cutoff was present in $27 \%$ of lesions highly probable to have a thrombus (Group 2) as compared to $7 \%$ of lesions not highly probable for a coronary thrombus (Not-Group 2) (OR = 3, 95\% CI 1.12-6.57, $\mathrm{p}=0.03$, Table 4). Abrupt vessel cutoff was present in $2 \%$ of lesions highly unlikely to have a coronary thrombus (Group 3) (Table 5). Abrupt vessel cutoff was $32-59 \%$ sensitive and $92-94 \%$ specific for histologically confirmed or lesions highly probable for coronary thrombus (Tables 3,4 ).
Table 2. Clinical characteristics of study subjects $(n=76)$.

\begin{tabular}{lc}
\hline Characteristics & $\begin{array}{c}\text { Subjects with } \\
\text { qualifying } \\
\text { lesions* }\end{array}$ \\
\hline Demographics & $50(65.8 \%)$ \\
Males & \\
Medical history & $20(26.3 \%)$ \\
Diabetes & $57(75.0 \%)$ \\
Hypertension & $48(63.2 \%)$ \\
Dyslipidemia & $36(47.4 \%)$ \\
Atherosclerosis & $8(10.5 \%)$ \\
Congestive heart failure & $6(7.9 \%)$ \\
Chronic renal failure & $9(11.8 \%)$ \\
Stroke & $55(72.4 \%)$ \\
ESC/ACCF/AHAMHF acute MI & $71(94.7 \%)$ \\
Cardiac ischemic symptoms & \\
Vitals and laboratory at enrollment & $136.7 \pm 29.1$ \\
Systolic blood pressure & $78.6 \pm 21.1$ \\
Diastolic blood pressure & $29.2 \pm 6.5$ \\
Body mass index & $48.8 \pm 14.1$ \\
Ejection fraction & $33(34.2 \%)$ \\
ST elevation & $14(18.4 \%)$ \\
ST depression & $50(65.8 \%)$ \\
Elevated troponin & $17(22.4 \%)$ \\
Non-elevated troponin§ & $52(68.4 \%)$ \\
Lesions $>50 \%$ stenosis & $52(68.4 \%)$ \\
Lesions $>70 \%$ stenosis & $66(86.8 \%)$ \\
Aspirin & $42(55.3 \%)$ \\
P2Y12 Inhibitor & $34(44.7 \%)$ \\
Betatin & $26.2 \%)$ \\
\hline
\end{tabular}

ACCF - American College of Cardiology Foundation; AHA American Heart Association; ESC - European Society of Cardiology; MI - myocardial infarction; WHF - World Health Federation Atherosclerosis - myocardial infarction, coronary artery disease, percutaneous intervention, coronary artery bypass graft Stroke - carotid endarterectomy, peripheral artery disease, aortic aneurysm

*Lesions with $\geq 10 \%$ stenosis

'Symptoms prior to cardiac catheterization — localized/radiating pain/discomfort; dyspnea; diaphoresis; nausea; light headedness; syncope

${ }^{\ddagger}$ Elevated troponin - Ortho Vitros 5600 assay $=0.12 \mathrm{ng} / \mathrm{mL}$ and Beckman Access assay $=0.5 \mathrm{ng} / \mathrm{mL}$

${ }^{\S}$ Non-elevated troponin - Ortho Vitros 5600 assay $\leq 0.035 \mathrm{ng} / \mathrm{mL}$ and Beckman Access assay $\leq 0.04 \mathrm{ng} / \mathrm{mL}$

\section{Intraluminal staining}

Intraluminal staining was present in $35 \%$ of lesions with histologically confirmed thrombus (Group 1) as compared to $1 \%$ of lesions without histologically confirmed thrombus (Not-Group 1) 
Table 3. Comparisons of thrombotic angiographic characteristics between lesions in Group 1 and Not-Group 1.

\begin{tabular}{|c|c|c|c|c|c|c|}
\hline \multirow[t]{2}{*}{ Characteristics } & \multicolumn{6}{|c|}{$\begin{array}{l}\text { Group } 1 \text { (n }=23 \text { ) (histologically confirmed thrombus) vs. Not-Group } 1 \\
\qquad(n=300)\end{array}$} \\
\hline & $\begin{array}{c}\text { Group } 1 \\
N(\%)\end{array}$ & $\begin{array}{c}\text { Not-Group } 1 \\
\text { N (\%) }\end{array}$ & $\begin{array}{c}\text { GEE OR } \\
(95 \% \mathrm{CI})\end{array}$ & $\mathbf{P}$ & $\begin{array}{l}\text { Sensitivity } \\
\%(95 \% \mathrm{Cl})\end{array}$ & $\begin{array}{l}\text { Specificity } \\
\%(95 \% \text { CI) }\end{array}$ \\
\hline $\begin{array}{l}\text { Complex Ambrose } \\
\text { morphology }\end{array}$ & $1(4.4)$ & $18(6.0)$ & $\begin{array}{c}1.02 \\
(0.12,8.74)\end{array}$ & 1.0 & $7(1,37)$ & $93(89,95)$ \\
\hline $\begin{array}{l}\text { Presence of spherical, ovoid } \\
\text { or irregular filling defect }\end{array}$ & $9(39.1)$ & $2(0.7)$ & $\begin{array}{c}206 \\
(36.5,1161)\end{array}$ & $<0.0001$ & $55(31,76)$ & $99(97,100)$ \\
\hline $\begin{array}{l}\text { Presence of abrupt vessel cutoff } \\
\text { with persistence of contrast }\end{array}$ & $14(60.9)$ & $24(8.0)$ & $\begin{array}{c}18.1 \\
(6.64,49.1)\end{array}$ & $<0.0001$ & $59(38,77)$ & $92(88,95)$ \\
\hline $\begin{array}{l}\text { Presence of intraluminal } \\
\text { staining }\end{array}$ & $8(34.8)$ & $4(1.3)$ & $\begin{array}{c}44.9 \\
(13.4,151)\end{array}$ & $<0.0001$ & $36(19,58)$ & $99(97,100)$ \\
\hline $\begin{array}{l}\text { Presence of any coronary } \\
\text { filling defect* }\end{array}$ & $11(47.8)$ & $8(2.7)$ & $\begin{array}{c}69 \\
(20.4,234)\end{array}$ & $<0.0001$ & $60(37,79)$ & $97(95,99)$ \\
\hline
\end{tabular}

GEE OR - generalized estimating equations-estimated odds ratio between groups; $\mathrm{Cl}$ - confidence interval

Group 1 - individual lesions with histologically confirmed thrombus

*Any coronary filling defect includes spherical, ovoid, irregular, hazy, occlusive filling defects and obstructive coronary dissections

Table 4. Comparisons of thrombotic angiographic characteristics between lesions in Group 2 and Not-Group 2.

\begin{tabular}{|c|c|c|c|c|c|c|}
\hline \multirow[t]{2}{*}{ Characteristics } & \multicolumn{6}{|c|}{$\begin{array}{l}\text { Group } 2 \text { ( } n=73 \text { ) (highly probable coronary thrombus) vs. Not-Group } 2 \\
\qquad(n=250)\end{array}$} \\
\hline & $\underset{N(\%)}{\text { Group }} 2$ & $\begin{array}{l}\text { Not-Group } 2 \\
\text { N }(\%)\end{array}$ & $\begin{array}{l}\text { GEE OR } \\
(95 \% \mathrm{CI})\end{array}$ & $\mathbf{P}$ & $\begin{array}{l}\text { Sensitivity } \\
\%(95 \% \mathrm{CI})\end{array}$ & $\begin{array}{l}\text { Specificity } \\
\%(95 \% \mathrm{Cl})\end{array}$ \\
\hline $\begin{array}{l}\text { Complex Ambrose } \\
\text { morphology }\end{array}$ & $5(6.9)$ & $14(5.6)$ & $\begin{array}{c}1.07 \\
(0.9,1.31)\end{array}$ & 0.5 & $14(8,23)$ & $94(89,96)$ \\
\hline $\begin{array}{l}\text { Presence of spherical, ovoid } \\
\text { or irregular filling defect }\end{array}$ & $10(13.7)$ & $1(0.4)$ & $\begin{array}{c}60.8 \\
(3.84,961)\end{array}$ & 0.004 & $22(13,35)$ & $100(96,100)$ \\
\hline $\begin{array}{l}\text { Presence of abrupt vessel cutoff } \\
\text { with persistence of contrast }\end{array}$ & $20(27.4)$ & $18(7.2)$ & $\begin{array}{c}2.72 \\
(1.12,6.57)\end{array}$ & 0.03 & $32(22,45)$ & $94(89,96)$ \\
\hline $\begin{array}{l}\text { Presence of intraluminal } \\
\text { staining }\end{array}$ & $9(12.3)$ & $3(1.2)$ & $\begin{array}{c}8.18 \\
(2.12,31.6)\end{array}$ & 0.002 & $17(9,29)$ & $99(97,100)$ \\
\hline $\begin{array}{l}\text { Presence of any coronary filling } \\
\text { defect }^{*}\end{array}$ & $14(19.2)$ & $5(2.0)$ & $\begin{array}{c}8.53 \\
(2.7,26.9)\end{array}$ & 0.0003 & $26(16,39)$ & $98(95,99)$ \\
\hline
\end{tabular}

GEE OR - generalized estimating equations-estimated odds ratio between groups; $\mathrm{Cl}$ - confidence interval

Group 2 - individual lesions with highly probable coronary thrombus [ST elevation in territory of $>70 \%$ stenosis and elevated troponin]

*Any coronary filling defect includes spherical, ovoid, irregular, hazy, occlusive filling defects and obstructive coronary dissections

$(\mathrm{OR}=45,95 \%$ CI $13.4-151, \mathrm{p}<0.0001$, Table 3$)$. Intraluminal staining was present in $12 \%$ of lesions highly probable for a coronary thrombus (Group 2) as compared to $1 \%$ of lesions not highly probable for a coronary thrombus (Not-Group 2$)(\mathrm{OR}=8$, $95 \%$ CI 2.12-31.6, $\mathrm{p}=0.002$, Table 4). Intraluminal staining was absent in all lesions highly unlikely to have a coronary thrombus (Table 5). Intraluminal staining was $17-36 \%$ sensitive and $99 \%$ specific for histologically confirmed or lesions highly probable for coronary thrombus (Tables 3,4 ).

\section{Any coronary filling defect}

Any coronary filling defect was present in $48 \%$ of lesions with histologically confirmed thrombus (Group 1) as compared to $3 \%$ of lesions without histologically confirmed thrombus (Not-Group 1) $(\mathrm{OR}=69,95 \%$ CI 20.4-234, $\mathrm{p}<0.0001$, Table 3$)$. Any coronary filling defect was present in $19 \%$ of lesions highly probable for a coronary thrombus (Group 2) and 2\% of lesions not highly probable for a coronary thrombus (Not-Group 2$)(\mathrm{OR}=9,95 \%$ CI $2.7-26.9, \mathrm{p}=0.0002$, Table 4 ). Any coronary 
Table 5. Comparisons of thrombotic angiographic characteristics between lesions in Group 3 and Not-Group 3.

\begin{tabular}{|c|c|c|c|c|c|c|}
\hline \multirow[t]{2}{*}{ Characteristics } & \multicolumn{6}{|c|}{$\begin{array}{c}\text { Group } 3(n=61) \text { (highly-unlikely to have a coronary thrombus) } \\
\text { vs. Not Group-3 }(n=262)\end{array}$} \\
\hline & $\begin{array}{c}\text { Group } 3 \\
N(\%)\end{array}$ & $\begin{array}{c}\text { Not-Group } 3 \\
\text { N (\%) }\end{array}$ & $\begin{array}{c}\text { GEE OR } \\
(95 \% \mathrm{CI})\end{array}$ & $\mathbf{P}$ & $\begin{array}{l}\text { Sensitivity } \\
\%(95 \% \mathrm{Cl})\end{array}$ & $\begin{array}{l}\text { Specificity } \\
\%(95 \% \text { CI) }\end{array}$ \\
\hline $\begin{array}{l}\text { Complex Ambrose } \\
\text { morphology }\end{array}$ & $3(4.9)$ & $16(6.1)$ & $\begin{array}{c}1.06 \\
(0.669,1.69)\end{array}$ & 0.8 & $93(81,98)$ & $8(5,13)$ \\
\hline $\begin{array}{l}\text { Presence of spherical, ovoid } \\
\text { or irregular filling defect }\end{array}$ & $0(0.0)$ & $11(4.2)$ & $\begin{array}{c}1.46 \\
(0.817,2.62)^{\dagger}\end{array}$ & 0.2 & $98(87,100)$ & $5(3,9)$ \\
\hline $\begin{array}{l}\text { Presence of abrupt vessel cutoff } \\
\text { with persistence of contrast }\end{array}$ & $1(1.6)$ & $37(14.1)$ & $\begin{array}{c}1.59 \\
(1.23,2.06)\end{array}$ & $<0.0004$ & $97(90,99)$ & $14(10,19)$ \\
\hline $\begin{array}{l}\text { Presence of intraluminal } \\
\text { staining }\end{array}$ & $0(0.0)$ & $12(4.6)$ & $\begin{array}{c}1.32 \\
(0.803,2.17)^{\dagger}\end{array}$ & 0.3 & $98(87,100)$ & $5(3,8)$ \\
\hline $\begin{array}{l}\text { Presence of any coronary } \\
\text { filling defect* }\end{array}$ & $1(1.6)$ & $18(6.9)$ & $\begin{array}{c}1.45 \\
(1.01,1.98)\end{array}$ & 0.046 & $97(83,100)$ & $7(5,11)$ \\
\hline
\end{tabular}

GEE OR - Generalized Estimating Equation- estimated odds ratio between groups; $\mathrm{Cl}$ - confidence interval

Group 3 - individual lesions highly unlikely to have a coronary thrombus (no ST elevation, non-elevated troponin, no histologically confirmed thrombus)

*Any coronary filling defect includes spherical, ovoid, irregular, hazy, occlusive filling defects and obstructive coronary dissections ${ }^{\dagger}$ Conservative estimate generated by adding one event to zero-count cell

filling defect was present in $2 \%$ of lesions highly unlikely to have a coronary thrombus (Group 3) (Table 5). Any coronary filling defect was $26-60 \%$ sensitive and $97-98 \%$ specific for histologically confirmed or lesions highly probable for coronary thrombosis (Tables 3,4 ).

\section{Discussion}

In this prospective study of 80 subjects with acute MI or stable CAD undergoing coronary angiography, there were four major findings with important clinical implications. First, Ambrose morphology failed to differentiate between thrombotic and non-thrombotic lesions. Second, the remaining four characteristics (spherical, ovoid, or irregular filling defect; abrupt vessel cutoff; intraluminal staining; and any coronary filling defect) were consistently more common and highly specific (92-100\%) for thrombotic vs. non-thrombotic lesions. Third, spherical, ovoid, or irregular filling defect and intraluminal staining had highest specificities (99-100\%) for the presence of a thrombotic lesion. Fourth, spherical, ovoid, or irregular filling defect and intraluminal staining were present in $<40 \%$ of all thrombotic lesions, hence a high specificity (99-100\%) but low sensitivity ( $\leq 55 \%)$ for identifying coronary thrombus in this cohort. Thus, in the right clinical context, their presence is highly suggestive of coronary thrombus, while their absence does not rule out an acute coronary thrombus.
Although the five characteristics evaluated in this study have been ubiquitous in the angiographic literature for decades $[12,13,16,18,19]$, validation studies against histological confirmation of thrombus are limited. In a post-mortem study of lesion morphology, Levin et al. [22], found that $79 \%$ of lesions consistent with complex Ambrose lesion morphology were associated with "complicated" histology, which were comprised of plaque rupture and or hemorrhage without thrombosis. However, that study was limited by the unknown time between death and post-mortem coronary angiography in addition to the fact that angiography differs between post-mortem and a live-beating heart. The association between Ambrose complex lesion morphology and unstable angina has been described [10, 12, 23-26]. Recently, Ambrose et al. [27] reported that there exists an association between complex morphology and thrombotic/Type 1 MI, rather than non-thrombotic/Type $2 \mathrm{MI}$, which is consistent with previous reports that complex lesions represent ruptured atherosclerotic plaque, partially occlusive thrombi, or both [26]. However, when superior imaging modalities like angioscopy or intravascular ultrasound (IVUS) are used to validate the presence of a coronary thrombus, the specificity of complex Ambrose morphology for identification of a coronary thrombus is limited [28-30]. In our study, we did not find a significant relationship between complex Ambrose morphology and acute coronary thrombosis (Group 1 or Group 2 lesions). Ambrose morphology criteria 
may be better suited for identifying lesions associated with myocardial ischemia [16, 29], rather than for confirmation of an acute coronary thrombus.

Rehr et al. [31] defined intracoronary thrombus as presence of abrupt vessel cutoff with contrast persistence and intraluminal filling defect to differentiate unstable angina from stable angina. They found that the sensitivity for detecting a thrombus in the unstable angina group was low $(42 \%)$ and the specificity was moderate $(83 \%)$. Both of these characteristics were evaluated, i.e. abrupt vessel cutoff with contrast persistence and any coronary filling defect, individually in this study it was found that although the sensitivity of both the characteristics to identify thrombotic lesions was also low (26-60\%), their specificity to identify thrombotic lesions was high (92-98\%).

DeWood et al. [28] studied angiographic detection of coronary thrombus in 79 STEMI patients undergoing emergent surgical revascularization and found that $75 \%$ of patients had persistent angiographic intraluminal staining, and $88 \%$ of those with intraluminal staining had a thrombus recovered. These results are similar to findings in our study wherein intraluminal staining was present in significantly higher number of thrombotic lesions (Group 1 or Group 2) than non-thrombotic lesions (Not-Group 1 or Not-Group 2). Mabin et al. [32] used the presence of intraluminal filling defect and intraluminal staining as key criteria for detecting intracoronary thrombus in patients undergoing percutaneous angioplasty. In the study by Mabin et al. [32], out of the 15 patients angiographically diagnosed with an intracoronary thrombus, 11 (73\%) were confirmed to have coronary thrombus via emergent surgical intervention (coronary artery bypass grafting). The presence of both these characteristics, i.e. any filling defect and intraluminal staining, in the histologically confirmed thrombus group (Group 1) of our study was low ( $\leq 48 \%$ ). However, the specificity of intraluminal staining for thrombotic lesions (Group 1 or Group 2) was high (99\%).

A spherical, ovoid, or irregular filling defect and intraluminal staining were found almost exclusively in groups with thrombotic lesions. However, both of these characteristics were present in fewer than $40 \%$ of all thrombotic lesions (Group 1 and Group 2), hence good specificity (99-100\%) but poor sensitivity ( $\leq 55 \%$ ) for identifying coronary thrombus in the present cohort. Both of these characteristics were significantly associated with thrombotic lesion groups (Group 1 or Group 2) and only rarely with non-thrombotic lesion groups
(Group 3, Not-Group 1, Not-Group 2). Therefore, the presence of either of these angiographic characteristics holds great promise for aiding in the diagnosis of coronary thrombus and warrants validation in an independent cohort. On the other hand, their absence does not rule out coronary thrombus in the right clinical context.

\section{Limitations of the study}

There is no gold standard for identifying the presence of a coronary thrombus except nearimmediate autopsy, which is only applicable to a select group of patients who die shortly after coronary angiography. Post-mortem angiography is of questionable relevance. In this study, standard-of-care coronary aspiration thrombectomy was employed, however, the decision to perform thrombectomy and the ensuing technique was left to the discretion of the interventional cardiologist [33, 34]. Furthermore, coronary aspiration thrombectomy may fail to capture thrombi in some cases [20]. Therefore criteria was introduced for the diagnosis of coronary thrombus that included histologically confirmed thrombus (Group 1) or a combination of electrocardiographic (ST-segment elevation), biochemical (elevated troponin) and coronary stenosis (> 70\%) criteria (Group 2). Other techniques available for the identification of thrombi that were not employed in this study include IVUS, optical coherence tomography, and angioscopy; however, these techniques are limited by availability, the inability to cover the entire epicardial coronary circulation, and the limited amount (or total lack) of validation data with histologically confirmed thrombi [35, 36].

Finally, this was not a study of all patients undergoing cardiac catheterization, but rather of a group of select patients with acute MI or stable CAD. Therefore, further study is required in the applicability of our findings to all patients suspected of acute MI undergoing coronary angiography.

\section{Conclusions}

Four of the five angiographic characteristics evaluated in this cohort were associated with acute coronary thrombus, as defined by histological analysis or a combination of histology, ST-segment elevation, troponin elevation and coronary stenosis. The presence of either spherical, ovoid, or irregular filling defect or intraluminal staining is highly specific (99-100\%) for the presence of thrombotic lesions but these characteristics were present in $<40 \%$ of thrombotic lesions and 
therefore are not sensitive $(\leq 55 \%)$ for identifying coronary thrombus. Validation of these findings in an independent cohort to establish whether these characteristics can be used to help establish the diagnosis of acute coronary thrombus in clinical practice is warranted.

\section{Acknowledgements}

Thanks go to all of the subjects who generously consented to participate in this study. The efforts of all personnel involved in data collection and management are much appreciated. The authors are also grateful for the support provided by the Diabetes and Obesity Center, University of Louisville; the University of Louisville; the University of Louisville Hospital and the KentuckyOne Health Jewish Hospital.

Funding sources: This study was supported by research grants from the American Heart Association (11CRP7300003) and the National Institutes of Health (1P20 GM103492).

\section{Conflict of interest: None declared}

\section{References}

1. Corti R, Fuster V and Badimon JJ. Pathogenetic concepts of acute coronary syndromes. J Am Coll Cardiol, 2003; 41: 7S-14S.

2. Newby LK, Jesse RL, Babb JD et al. ACCF 2012 expert consensus document on practical clinical considerations in the interpretation of troponin elevations: a report of the American College of Cardiology Foundation task force on Clinical Expert Consensus Documents. J Am Coll Cardiol, 2012; 60: 2427-2463.

3. Larson DM, Menssen KM, Sharkey SW et al. "False-positive" cardiac catheterization laboratory activation among patients with suspected ST-segment elevation myocardial infarction. JAMA, 2007; 298: 2754-2760.

4. Keller T, Zeller T, Peetz D et al. Sensitive troponin I assay in early diagnosis of acute myocardial infarction. New Engl J Med, 2009; 361: 868-877.

5. Hammarsten O, Fu ML, Sigurjonsdottir R et al. Troponin T percentiles from a random population sample, emergency room patients and patients with myocardial infarction. Clin Chem, 2012; 58: 628-637.

6. Thygesen K, Alpert JS, Jaffe AS et al. Third universal definition of myocardial infarction. Circulation, 2012; 126: 2020-2035.

7. Hancock EW, Deal BJ, Mirvis DM et al. AHA/ACCF/HRS recommendations for the standardization and interpretation of the electrocardiogram: part V: electrocardiogram changes associated with cardiac chamber hypertrophy: a scientific statement from the American Heart Association Electrocardiography and Arrhythmias Committee, Council on Clinical Cardiology; the American College of Cardiology Foundation; and the Heart Rhythm Society: endorsed by the International Society for Computerized Electrocardiology. Circulation, 2009; 119: e251$-\mathrm{e} 261$.
8. Sgarbossa EB, Pinski SL, Barbagelata A et al. Electrocardiographic diagnosis of evolving acute myocardial infarction in the presence of left bundle-branch block. GUSTO-1 (Global Utilization of Streptokinase and Tissue Plasminogen Activator for Occluded Coronary Arteries) Investigators. New Engl J Med, 1996; 334: 481-487.

9. Wagner GS, Macfarlane P, Wellens $\mathrm{H}$ et al. AHA/ACCF/HRS recommendations for the standardization and interpretation of the electrocardiogram: part VI: acute ischemia/infarction: a scientific statement from the American Heart Association Electrocardiography and Arrhythmias Committee, Council on Clinical Cardiology; the American College of Cardiology Foundation; and the Heart Rhythm Society: endorsed by the International Society for Computerized Electrocardiology. Circulation, 2009; 119: e262-e270.

10. Ambrose JA, Almeida OD, Sharma SK, Dangas G, Ratner DE. Angiographic evolution of intracoronary thrombus and dissection following percutaneous transluminal coronary angioplasty (the Thrombolysis and Angioplasty in Unstable Angina [TAUSA] trial). Am J Cardiol, 1997; 79: 559-563.

11. Ambrose JA, Almeida OD, Sharma SK et al. Adjunctive thrombolytic therapy during angioplasty for ischemic rest angina. Results of the TAUSA Trial. TAUSA Investigators. Thrombolysis and Angioplasty in Unstable Angina trial. Circulation, 1994; 90: 69-77.

12. Ambrose JA, Israel DH. Angiography in unstable angina. Am J Cardiol, 1991; 68: 78B-84B.

13. Capone G, Wolf NM, Meyer B, Meister SG. Frequency of intracoronary filling defects by angiography in angina pectoris at rest. Am J Cardiol, 1985; 56: 403-406.

14. Gibson CM, Cannon CP, Murphy SA et al. Relationship of the TIMI myocardial perfusion grades, flow grades, frame count, and percutaneous coronary intervention to long-term outcomes after thrombolytic administration in acute myocardial infarction. Circulation, 2002; 105: 1909-1913.

15. Gibson CM, Cannon CP, Murphy SA et al. Relationship of TIMI myocardial perfusion grade to mortality after administration of thrombolytic drugs. Circulation, 2000; 101: 125-130.

16. Goldstein JA, Demetriou D, Grines CL, Pica M, Shoukfeh M, O'Neill WW. Multiple complex coronary plaques in patients with acute myocardial infarction. New Engl J Med, 2000; 343: 915-922.

17. Protocol for the Bypass Angioplasty Revascularization Investigation (BARI). Circulation, 1991; 84 (Suppl. V): V1-V27.

18. Zack PM, Ischinger T, Aker UT, Dincer B, Kennedy HL. The occurrence of angiographically detected intracoronary thrombus in patients with unstable angina pectoris. Am Heart J, 1984; 108: 1408-1412.

19. Dangas G, Mehran R, Wallenstein S et al. Correlation of angiographic morphology and clinical presentation in unstable angina. J Am Coll Cardiol, 1997; 29: 519-525.

20. Vink MA, Kramer MC, Li X et al. Clinical and angiographic predictors and prognostic value of failed thrombus aspiration in primary percutaneous coronary intervention. JACC Cardiovascular Interventions, 2011; 4: 634-642.

21. Troxler S, Lalonde T, Wilson JR. Exact logistic models for nested binary data. Stat Med, 2011; 30: 866-876.

22. Levin DC, Fallon JT. Significance of the angiographic morphology of localized coronary stenoses: histopathologic correlations. Circulation, 1982; 66: 316-320.

23. Ambrose JA, Hjemdahl-Monsen C, Borrico S et al. Quantitative and qualitative effects of intracoronary streptokinase in unstable 
angina and non-Q wave infarction. J Am Coll Cardiol, 1987; 9: 1156-1165.

24. Ambrose JA, Hjemdahl-Monsen CE, Borrico S, Gorlin R, Fuster V. Angiographic demonstration of a common link between unstable angina pectoris and non-Q-wave acute myocardial infarction. Am J Cardiol, 1988; 61: 244-247.

25. Ambrose JA, Winters SL, Arora RR et al. Angiographic evolution of coronary artery morphology in unstable angina. J Am Coll Cardiol, 1986; 7: 472-478.

26. Ambrose JA, Winters SL, Stern A et al. Angiographic morphology and the pathogenesis of unstable angina pectoris. J Am Coll Cardiol, 1985; 5: 609-616.

27. Ambrose JA, Loures-Vale A, Javed U, Buhari CF, Aftab W. Angiographic correlates in type 1 and 2 MI by the universal definition. JACC Cardiovasc Imaging, 2012; 5: 463-464.

28. DeWood MA, Spores J, Notske R et al. Prevalence of total coronary occlusion during the early hours of transmural myocardial infarction. New Engl J Med, 1980; 303: 897-902.

29. Guazzi MD, Bussotti M, Grancini L et al. Evidence of multifocal activity of coronary disease in patients with acute myocardial infarction. Circulation, 1997; 96: 1145-1151.

30. Refaat H, Niccoli G, Gramegna M et al. Optical coherence tomography features of angiographic complex and smooth lesions in acute coronary syndromes. Int J Cardiovasc Imaging, 2015; 31: 927-934
31. Rehr R, Disciascio G, Vetrovec G, Cowley M. Angiographic morphology of coronary artery stenoses in prolonged rest angina: evidence of intracoronary thrombosis. J Am Coll Cardiol, 1989; 14: 1429-1437.

32. Mabin TA, Holmes DR, Jr, Smith HC et al. Intracoronary thrombus: Role in coronary occlusion complicating percutaneous transluminal coronary angioplasty. J Am Coll Cardiol, 1985; 5: 198-202.

33. Anderson JL, Adams CD, Antman EM et al. 2011 ACCF/AHA Focused Update Incorporated Into the ACC/AHA 2007 Guidelines for the Management of Patients With Unstable Angina/Non-ST-Elevation Myocardial Infarction: a report of the American College of Cardiology Foundation/American Heart Association Task Force on Practice Guidelines. Circulation, 2011; 123: e426-e579.

34. American College of Emergency P, Society for Cardiovascular A, Interventions, et al. $2013 \mathrm{ACCF} / \mathrm{AHA}$ guideline for the management of ST-elevation myocardial infarction: a report of the American College of Cardiology Foundation/American Heart Association Task Force on Practice Guidelines. J Am Coll Cardiol, 2013; 61: e78-e140.

35. Kubo T, Imanishi T, Takarada S et al. Assessment of culprit lesion morphology in acute myocardial infarction: ability of optical coherence tomography compared with intravascular ultrasound and coronary angioscopy. J Am Coll Cardiol, 2007; 50: 933-939.

36. Maehara A, Mintz GS, Weissman NJ. Advances in intravascular imaging. Circulation Cardiovascular Interventions, 2009; 2: 482-490. 